\title{
Characterization and Antimicrobial Susceptibility of Actinomycetes from TB Smear Negative and Retreatment Patients in Nairobi, Kenya
}

\author{
Frida M. Njeru'1,2*, Perpetual Ndungu ${ }^{3}$, Christine Bii² \\ ${ }^{1}$ Institute of Tropical Medicine and Infectious Diseases, Jomo Kenyatta University of Agriculture and Technology, Nairobi, Kenya \\ ${ }^{2}$ Centre for Microbiology Research, Kenya Medical Research Institute, Nairobi, Kenya \\ ${ }^{3}$ Department of Biomedical Sciences, Jomo Kenyatta University of Agriculture and Technology, Nairobi, Kenya \\ Email: ${ }^{\star}$ fnmunene@gmail.com
}

How to cite this paper: Njeru, F.M., Ndungu, P. and Bii, C. (2019) Characterization and Antimicrobial Susceptibility of Actinomycetes from TB Smear Negative and Retreatment Patients in Nairobi, Kenya. Journal of Biosciences and Medicines, 7 , 1-12.

https://doi.org/10.4236/jbm.2019.78001

Received: June 21, 2019

Accepted: August 6, 2019

Published: August 9, 2019

Copyright $\odot 2019$ by author(s) and Scientific Research Publishing Inc. This work is licensed under the Creative Commons Attribution International License (CC BY 4.0).

http://creativecommons.org/licenses/by/4.0/

\begin{abstract}
Actinomycetes are opportunistic pathogens in immunosuppressive patients. Pulmonary actinomycetes infections display symptoms that mimic Mycobacteria tuberculosis and can be misdiagnosed and treated as pulmonary TB. Actinomycetes can be co-infection with tuberculosis leading to delayed or inappropriate treatment. This study aimed to identify and determine antimicrobial susceptibility profiles of Actinomycetes from the sputum of TB smear negative and re-treatment patients referred to TB reference facilities in Kenya. Sputum specimens were collected and direct smears stained with Gram's reagents. Culture was done on Mueller Hinton agar and incubated at $35^{\circ} \mathrm{C}$ for two weeks. Identification was done using phenotypic and biochemical procedures. Confirmation of the isolates was done using Polymerase Chain Reaction. A total of 52/385 (14\%) Actinomycetes were isolated and subjected to antimicrobial susceptibility testing using broth microdilution method to determine the Minimum Inhibitory Concentration. Nine antibiotics were tested which included: Amikacin, Amoxicillin/Clavulanic acid, Ceftriaxone, Ciprofloxacin, Clarithromycin, Linezolid, Doxycycline, Trimethoprim-Sulfamethoxazole and Gentamycin. Staphylococcus aureus (ATCC 25923) was used as a control. Most of the isolates were susceptible to the test antibiotics. However, four isolates showed multidrug resistance to Ceftriaxone and Clarithromycin with resistance of $11.5 \%$ and $26.9 \%$ respectively. Gentamycin and Ciprofloxacin showed the highest susceptibility of $100 \%$ and 98.1\% respectively. The findings of this study confirm that Actinomycetes are significant pathogens in TB smear-negative cases. Although most antibiotics were susceptible, resistance to few antibiotics was observed; hence, there is a
\end{abstract}


need for proper screening of TB smear-negative cases to detect infections by Actinomycetes and also conduct the antimicrobial susceptibility test to determine which antibiotic is effective.

\section{Keywords}

Actinomycetes, Tuberculosis, Antibiotics, Resistance, Kenya

\section{Introduction}

Actinomycetes are a group of aerobic and anaerobic bacteria belonging to the order Actinomycetales. Most of the aerobic Actinomycetes are Gram positive, filamentous, partially acid-fast, and relatively slow-growing branched bacteria. They have many microbiologic characteristics in common with members of the genera Mycobacterium. They have a worldwide distribution and they exist as saprophytes in the soil and other natural habitats. They can be transmitted through the wind in the dust and dirt into the lungs or skin and cause infections [1]. Several species of aerobic Actinomycetes that cause infections in human and animals include: Nocardia, Gordona, Tsukamurella, Streptomyces, Rhodococcus, Actinomadura, and Corynebacteria; while the species of anaerobic Actinomycetes that are pathogenic to man and animals include Actinomyces, Arachnia, Rothia, and Bifidobacterium [2].

Most of the Actinomycetes are opportunistic pathogens with the majority of infections occurring in patients with immunosuppressive conditions. However, a low percentage of immunocompetent patients also get infected. The Actinomycetes that affect the respiratory mostly display symptoms that mimic TB; hence in most cases, they are misdiagnosed or regarded as contaminant or commensal organism. Therefore, patients end up not being treated or being treated with the wrong medication. Missed or delayed treatment leads to increased morbidity and mortality and promotes drug resistance. The mandate of the National and International Tuberculosis (TB) Control Programs is the detection and management of pulmonary TB. However, patients with clinical and radiological evidence of pulmonary TB but are repeatedly sputum smear-negative is a common clinical dilemma. Therefore, understanding the significance of Actinomycetes in TB-smear negative and retreatment cases is essential for reducing the morbidity, mortality and drug resistance associated with a missed diagnosis.

Therefore, the aim of this study was to isolate and determine the antimicrobial susceptibility profiles of Actinomycetes from TB smear negative and retreatment cases referred to TB reference facilities in Kenya.

\section{Materials and Methods}

\subsection{Study Site}

The samples were collected from the TB reference facilities from TB patients who were considered retreatment, relapse or smear negative from different parts 
of the Country. The Samples were analyzed at Kenya Medical Research Institute-Centre for Microbiology Research, Mycology Laboratory-Nairobi.

\subsection{Sampling}

Patients were purposively selected on criteria that they were retreatment cases, relapse and gene expert negative. Informed consent was obtained after which expectorated sputum was obtained from 385 assented patients.

\subsection{Phenotypic Characterization of Actinomycetes}

The sputum specimens were Gram stained and examined under X100 magnification for microscopic characteristics of Actinomycetes. The sputum samples were cultured on Mueller Hinton Agar and Sabouraud's dextrose agar (SDA) and incubated aerobically at $35^{\circ} \mathrm{C}$ ambient air. The cultures were observed periodically for growth for four weeks. Suspected colonies were identified by their chalky, firm and leathery texture [3] suspicious colonies were sub-cultured on fresh Mueller Hinton Agar plates and incubated at $35^{\circ} \mathrm{C}$ until sufficient growth was obtained. Pure colonies were then inoculated into $1.0 \mathrm{~mL}$ of $15 \%$ sterile glycerol stocking solution and stored at $-80^{\circ} \mathrm{C}$ for further analysis.

\subsection{Biochemical Characterization}

The suspected isolates with microscopic and cultural characteristics of Actinomycetes were subjected to the following biochemical tests; Casein hydrolysis, Simon citrate, urea hydrolysis and catalase test.

\subsection{Genomic DNA Extraction and PCR Amplification}

The stocked pure isolates were revived by culturing on Mueller Hinton agar plates and incubated at $35^{\circ} \mathrm{C}$ for 72 hours. A loop full of a single colony was picked for use in the extraction of the total genomic DNA. The extraction process was based on the Qiagen DNA Extraction kit protocol. The extracted DNA was stored at $-20^{\circ} \mathrm{C}$ for further analysis. The DNA from each isolate was used as a template for amplification of the $16 \mathrm{~S}$ rDNA gene which is a conserved gene in the bacteria [4]. The $16 \mathrm{~S}$ rDNA sequence was amplified using the following group specific pair of primers; F-Act 243 (5'-GGATGAGCCCGCGGCCTA-3') and R-Act A3 (5'-CCAGCCCCACCTTCGAC-3') [5]. The following profile was used to carry out the Amplifications: $10 \mathrm{~min}$ at $95^{\circ} \mathrm{C}$ and 35 cycles of $94^{\circ} \mathrm{C}$ for 1 $\min , 60^{\circ} \mathrm{C}$ for $1 \mathrm{~min}$ and $72^{\circ} \mathrm{C}$ for $1 \mathrm{~min}, 45 \mathrm{~s}$, followed by $15 \mathrm{~min}$ at $72^{\circ} \mathrm{C}$. Amplification products were analyzed by electrophoresis in $1.5 \%(\mathrm{w} / \mathrm{v})$ agarose gels stained with ethidium bromide and visualized under fluorescence light.

\subsection{Antimicrobial Susceptibility Testing}

Antimicrobial susceptibility testing was done using broth microdilution (BMD) method according to the CLSI guidelines for rapidly growing mycobacteria and aerobic Actinomycetes [6]. 


\subsubsection{Inoculum Preparation}

The revived fresh cultures were used for antimicrobial susceptibility testing. To achieve an optical density of a $0.5 \mathrm{McFarland}$ standard, pure colonies of the isolates were picked from a Mueller Hinton agar plate after $72 \mathrm{~h}$, using a sterile loop, and transferred to $2 \mathrm{ml}$ sterile water. The inoculum was then vortexed for 15 to 20 s for uniformity

\subsubsection{Broth Microdilution}

The antimicrobial agents tested included Amikacin $(64 \mu \mathrm{g} / \mathrm{ml})$, Amoxicillin-Clavulanate $(64 / 32 \mu \mathrm{g} / \mathrm{ml})$, Ceftriaxone $(256 \mu \mathrm{g} / \mathrm{ml})$, Ciprofloxacin (64 $\mu \mathrm{g} / \mathrm{ml})$, Clarithromycin $(64 \mu \mathrm{g} / \mathrm{ml})$, Gentamycin $(64 \mu \mathrm{g} / \mathrm{ml})$, Co-trimoxazole (Trimethoprim-Sulfamethoxazole) $(8 / 152 \mu \mathrm{g} / \mathrm{ml})$, Doxycycline $(64 \mu \mathrm{g} / \mathrm{ml})$ and Linezolid $(64 \mu \mathrm{g} / \mathrm{ml})$. Staphylococcus aureus ATCC 25923 was used for quality control. Briefly, Mueller Hinton broth was prepared and sterilized. Into sterile tubes, $4.9 \mathrm{ml}$ of sterile Mueller Hinton broth was dispensed. Three milliliters of the antimicrobial agents were added to $3 \mathrm{ml}$ of respective solvents (sterile water, DMSO, ethanol) and serially diluted to make a two-fold serial dilution. Into the $4.9 \mathrm{ml}$ Mueller Hinton broth, $0.1 \mathrm{ml}$ of the respective antimicrobial agents' dilutions was added to make a ten-fold dilution. Two hundred microliters of broth/antibiotics dilutions were then dispensed into wells of microtiter plates using a multichannel pipette. Ten microliters of the aforementioned inoculum were added to each well containing $200 \mu \mathrm{l}$ of Mueller-Hinton broth (MHB)/antibiotic dilution. Microtiter plates were sealed using parafilm and incubated at $35^{\circ} \mathrm{C}$ in ambient air. The MICs were read at $48 \mathrm{~h}$. If required due to poor growth, plates were re-incubated for a further $24 \mathrm{~h}$ and a final MIC reading was done after 72 hours. The MIC was defined as the lowest concentration of antimicrobial agent to inhibit visible growth.

\subsection{Statistical Analysis}

Statistical analysis was performed using a statistical package, R Windows version 3.5.2 by applying mean values using one-way ANOVA with post-hoc least square differences (LSD) method. A P value of less than 0.05 was considered significant.

\section{Results}

\subsection{Demographic Parameters of the Patients}

Out of 385 samples collected, 52 were positive for Actinomycetes by culture. The 52 cases were from different age groups with the youngest being 17 years and the oldest being 80 years old. Male were the most affected 33/52 (63\%) and female were 19/52 (37\%). Thirty nine (75\%) of the cases had a history of TB treatment (either on treatment, finished treatment, retreatment) while 13 (25\%) had no history of TB treatment. Table 1 below shows the cases based on age groups verses gender and history of treatment. 
Table 1. Demographics of the actinomycetes positive cases.

\begin{tabular}{|c|c|c|c|c|c|c|c|}
\hline \multirow[b]{3}{*}{ Age } & \multirow[b]{3}{*}{$\begin{array}{c}\text { No. of } \\
\text { cases }\end{array}$} & \multicolumn{4}{|c|}{ Gender/Clinical presentation } & \multirow[b]{3}{*}{$\begin{array}{c}\text { History } \\
\text { of TB } \\
\text { treatment }\end{array}$} & \multirow{3}{*}{$\begin{array}{c}\text { No } \\
\text { history } \\
\text { of TB } \\
\text { treatment }\end{array}$} \\
\hline & & \multicolumn{2}{|c|}{ Male } & \multicolumn{2}{|c|}{ Female } & & \\
\hline & & $\begin{array}{l}\text { With } \\
\text { History } \\
\text { of TB } \\
\text { treatment }\end{array}$ & $\begin{array}{c}\text { No } \\
\text { history } \\
\text { of TB } \\
\text { treatment }\end{array}$ & $\begin{array}{l}\text { With } \\
\text { History } \\
\text { of } \mathrm{TB} \\
\text { treatment }\end{array}$ & $\begin{array}{c}\text { No } \\
\text { history } \\
\text { of TB } \\
\text { treatment }\end{array}$ & & \\
\hline $\begin{array}{l}\text { Less than } \\
20 \text { yrs. }\end{array}$ & 4 & 0 & 2 & 1 & 1 & & \\
\hline $\begin{array}{c}20 \text { to } 29 \\
\text { yrs. }\end{array}$ & 16 & 6 & 2 & 5 & 3 & & \\
\hline $\begin{array}{c}30 \text { to } 39 \\
\text { yrs. }\end{array}$ & 11 & 8 & 1 & 2 & 0 & 39 (75\%) & $13(25 \%)$ \\
\hline $\begin{array}{c}40 \text { to } 49 \\
\text { yrs. }\end{array}$ & 11 & 7 & 0 & 4 & 0 & & \\
\hline $\begin{array}{c}50 \text { yrs. } \\
\text { and above }\end{array}$ & 10 & 4 & 3 & 2 & 1 & & \\
\hline Total & 52 & 33( & $3 \%)$ & & $7 \%)$ & & \\
\hline
\end{tabular}

\subsection{Isolated Actinomycetes}

The different phenotypic features of the isolated Actinomycetes on Mueller Hinton Agar are shown in Figure 1. All the isolates were gram-positive characteristic of Actinomycetes. The microscopic characteristics of representative Actinomycetes on gram stain are shown in Figure 2.

\subsection{Biochemical Test of Suspected Actinomycetes Isolates}

All isolates showed the ability to utilize citrate as the sole carbon source and were also all catalase positive hence the ability to breakdown hydrogen peroxide to oxygen and water. Most of them were able to produce urease enzyme while only a few of them were able to hydrolyze casein. Figure 3 and Figure 4 show casein and urease test respectively.

\subsection{Molecular Confirmation of the Isolates}

Confirmation of the isolated Actinomycetes was done by Polymerase Chain Reaction. The DNA extraction was done then PCR. The Gel image of amplified DNA of the representative isolates is shown in Figure 5.

\subsection{Antimicrobial Susceptibility Testing}

Antimicrobial Susceptibility Testing was done using nine antimicrobial agents which included broad-spectrum cephalosporin, first line and second line antibiotics. Minimum Inhibition Concentration was determined using broth micro dilution method. The antibiotic susceptibility is shown in Table 2 and representative MICs are indicated in Table 3. Most of the isolates were susceptible to most antibiotics. However, four isolates showed multidrug resistance. Ceftriaxone 


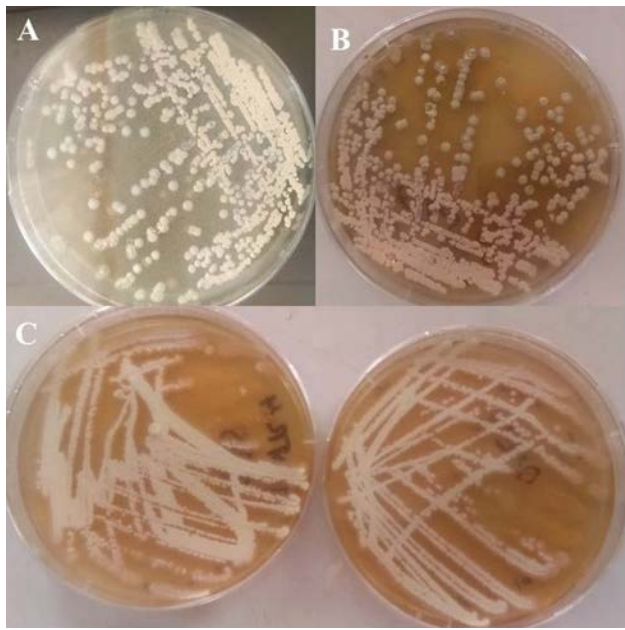

Figure 1. Culture. Typical colonies of Actinomycetes on Mueller Hinton agar. Plate (A) shows white wrinkled colonies while (B) and (C) show greyish whitish chalky colonies.

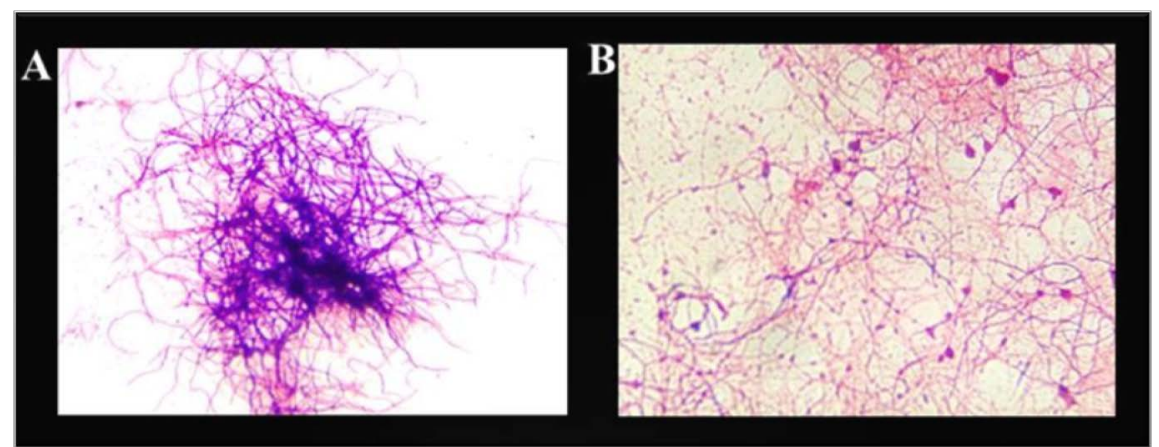

Figure 2. Gram Reactions of some of the Actinomycetes isolated. (A): Gram-positive intertwined filaments; (B): Gram-positive beaded branching filaments at power $\times 100$ magnification.

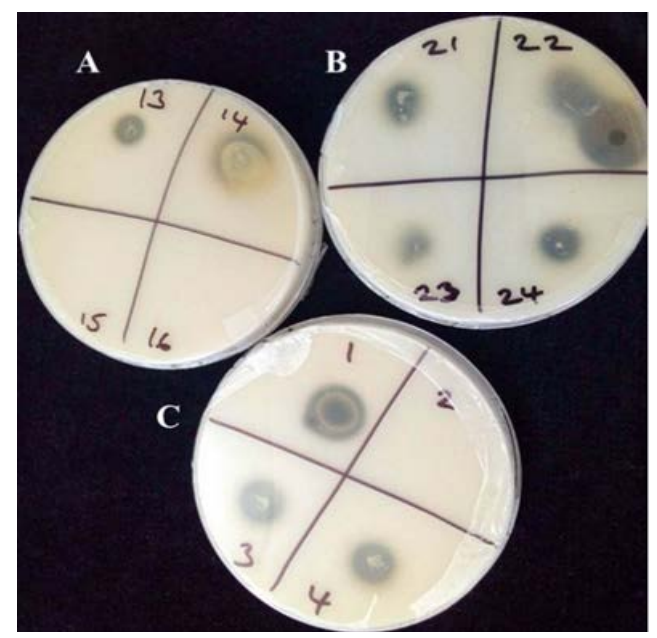

Figure 3. Casein test. Isolate 2, 15 and 16 are negative for casein hydrolysis while the rest are positive. 




Figure 4. Urease test of some of the isolated Actinomycete showing positive urease test. The last one is a negative control.



Figure 5. Representative gel image of amplified $16 \mathrm{~S}$ rDNA of isolated Actinomycetes. N is the negative control, $\mathrm{M}$ is hyperladder $1 \mathrm{~kb}$ Molecular Marker.

Table 2. Antibiotic susceptibility of the isolated actinomycetes.

\begin{tabular}{cccccccccc}
\hline \multirow{2}{*}{ Interpretations s } & \multicolumn{10}{c}{ ANTIBIOTICS } \\
\cline { 2 - 10 } & CIP & SXT & LZD & AMK & AMC & CN & CLA & DOXY & CRO \\
\hline Sensitive & $98.1 \%$ & $94.2 \%$ & $84.6 \%$ & $90.4 \%$ & $78.8 \%$ & $100 \%$ & $71.2 \%$ & $88.5 \%$ & $61.5 \%$ \\
Intermediate & $0 \%$ & $0 \%$ & $0 \%$ & $0 \%$ & $7.7 \%$ & $0 \%$ & $1.9 \%$ & $11.5 \%$ & $26.9 \%$ \\
Resistance & $1.9 \%$ & $5.8 \%$ & $15.4 \%$ & $9.6 \%$ & $13.5 \%$ & $0 \%$ & $26.9 \%$ & $0 \%$ & $11.5 \%$ \\
\hline
\end{tabular}

Key: CIP-Ciprofloxacin, SXT-Co-trimoxazole (Trimethoprim-Sulfamethoxazole), LZD-Linezolid, AMKAmikacin, AMC-Amoxicillin-Clavulanate, CN-Gentamycin, CLA-Clarithromycin, DOXY-Doxycycline, CRO-Ceftriaxone.

and Clarithromycin had the highest resistance; $11.5 \%$ and $26.9 \%$ respectively while Gentamycin and Ciprofloxacin showed the highest susceptibility; 100\% and $98.1 \%$ respectively. Interpretation of MICs was done according to CLSI guidelines. 
Table 3. The minimum inhibation concetrations of selected actinomycetes.

\begin{tabular}{|c|c|c|c|c|c|c|c|c|c|}
\hline \multirow{2}{*}{$\begin{array}{l}\text { LAB } \\
\text { NO. }\end{array}$} & \multicolumn{9}{|c|}{ ANTIBIOTIC PANEL TESTED AND MIC IN $\mu \mathrm{G} / \mathrm{ML}$} \\
\hline & CIP & SXT & LZD & AMK & AMC & $\mathrm{CN}$ & CLA & DOXY & CRO \\
\hline $\begin{array}{l}\text { ATCC } \\
25923\end{array}$ & $0.25 \mathrm{~S}$ & $9.5 \mathrm{~S}$ & $8 \mathrm{~S}$ & $4 \mathrm{~S}$ & $0.125 \mathrm{~S}$ & $1 \mathrm{~S}$ & $1 \mathrm{~S}$ & $0.5 \mathrm{~S}$ & $4 \mathrm{~S}$ \\
\hline $\mathrm{L} 228$ & $<0.062 \mathrm{~S}$ & $19 S$ & $4 \mathrm{~S}$ & $0.25 \mathrm{~S}$ & $<0.0625 \mathrm{~S}$ & $0.5 \mathrm{~S}$ & $<0.0625 \mathrm{~S}$ & $<0.0625 \mathrm{~S}$ & $4 \mathrm{~S}$ \\
\hline $\mathrm{L} 232$ & $0.125 \mathrm{~S}$ & $9.5 \mathrm{~S}$ & $8 \mathrm{~S}$ & $<0.0625 \mathrm{~S}$ & $16 \mathrm{I}$ & $0.25 \mathrm{~S}$ & $1 \mathrm{~S}$ & $<0.0625 \mathrm{~S}$ & $8 \mathrm{~S}$ \\
\hline L224 & $0.25 \mathrm{~S}$ & $19 S$ & $2 S$ & $4 \mathrm{~S}$ & $0.125 \mathrm{~S}$ & $0.125 \mathrm{~S}$ & $0.125 \mathrm{~S}$ & $0.125 \mathrm{~S}$ & $4 \mathrm{~S}$ \\
\hline L222 & $0.5 \mathrm{~S}$ & $9.5 \mathrm{~S}$ & $2 S$ & $16 \mathrm{R}$ & $4 \mathrm{~S}$ & $0.5 \mathrm{~S}$ & $32 \mathrm{R}$ & $0.5 \mathrm{~S}$ & $32 \mathrm{I}$ \\
\hline L171 & $0.125 \mathrm{~S}$ & $1.1875 \mathrm{~S}$ & $1 \mathrm{~S}$ & $1 \mathrm{~S}$ & $<0.0625 \mathrm{~S}$ & $0.25 \mathrm{~S}$ & $0.125 \mathrm{~S}$ & $0.25 \mathrm{~S}$ & $4 \mathrm{~S}$ \\
\hline L186 & $0.0625 \mathrm{~S}$ & $>76 \mathrm{R}$ & $>32 \mathrm{R}$ & $16 \mathrm{R}$ & $32 \mathrm{R}$ & $1 \mathrm{~S}$ & $>32 \mathrm{R}$ & $0.5 \mathrm{~S}$ & $64 \mathrm{R}$ \\
\hline L188 & $0.25 \mathrm{~S}$ & $>76 \mathrm{R}$ & $2 \mathrm{~S}$ & $16 \mathrm{R}$ & $>32 \mathrm{R}$ & $2 S$ & $0.5 \mathrm{~S}$ & $0.5 \mathrm{~S}$ & $64 \mathrm{R}$ \\
\hline L131 & $<0.0625 \mathrm{~S}$ & $9.5 \mathrm{~S}$ & $1 \mathrm{~S}$ & $0.25 \mathrm{~S}$ & $8 \mathrm{~S}$ & $<0.0625 \mathrm{~S}$ & $1 \mathrm{~S}$ & $<0.0625 \mathrm{~S}$ & $8 \mathrm{~S}$ \\
\hline L86 & $0.25 \mathrm{~S}$ & $9.5 \mathrm{~S}$ & $1 \mathrm{~S}$ & $<0.0625 \mathrm{~S}$ & $2 \mathrm{~S}$ & $<0.0625 \mathrm{~S}$ & $<0.0625$ S & $<0.0625 \mathrm{~S}$ & $4 \mathrm{~S}$ \\
\hline L51 & $1 \mathrm{~S}$ & $2.375 \mathrm{~S}$ & $1 \mathrm{~S}$ & $0.25 \mathrm{~S}$ & $32 \mathrm{R}$ & $<0.0625 \mathrm{~S}$ & $0.5 \mathrm{~S}$ & $1 \mathrm{~S}$ & $64 \mathrm{R}$ \\
\hline L29 & $1 \mathrm{~S}$ & $19 \mathrm{~S}$ & $2 \mathrm{~S}$ & $1 \mathrm{~S}$ & $32 \mathrm{R}$ & $0.125 \mathrm{~S}$ & $2 S$ & $0.0625 \mathrm{~S}$ & $64 \mathrm{R}$ \\
\hline $\mathrm{L} 230$ & $>32 \mathrm{R}$ & $>76 \mathrm{R}$ & $1 \mathrm{~S}$ & $8 \mathrm{~S}$ & $32 \mathrm{R}$ & $0.5 \mathrm{~S}$ & $32 \mathrm{R}$ & $2 \mathrm{I}$ & $16 \mathrm{I}$ \\
\hline L241 & $0.25 \mathrm{~S}$ & $19 \mathrm{~S}$ & $2 \mathrm{~S}$ & $8 \mathrm{~S}$ & $16 \mathrm{I}$ & $0.5 \mathrm{~S}$ & $32 \mathrm{R}$ & $2 \mathrm{I}$ & $16 \mathrm{I}$ \\
\hline L235 & $0.125 \mathrm{~S}$ & $4.75 \mathrm{~S}$ & $1 \mathrm{~S}$ & $2 S$ & $1 S$ & $0.5 \mathrm{~S}$ & $0.25 \mathrm{~S}$ & $1 \mathrm{~S}$ & $4 S$ \\
\hline L238 & $<0.0625 \mathrm{~S}$ & $9.5 \mathrm{~S}$ & $>32 \mathrm{R}$ & $0.5 \mathrm{~S}$ & $2 S$ & $0.25 \mathrm{~S}$ & $8 \mathrm{R}$ & $2 \mathrm{I}$ & $16 \mathrm{I}$ \\
\hline L341 & $0.25 \mathrm{~S}$ & $2.375 \mathrm{~S}$ & $>32 \mathrm{R}$ & $1 \mathrm{~S}$ & $1 \mathrm{~S}$ & $0.125 \mathrm{~S}$ & $0.25 \mathrm{~S}$ & $0.0625 \mathrm{~S}$ & $4 \mathrm{~S}$ \\
\hline L333 & $<0.0625 \mathrm{~S}$ & $4.75 \mathrm{~S}$ & $2 S$ & $16 \mathrm{R}$ & $8 \mathrm{~S}$ & $0.5 \mathrm{~S}$ & $1 \mathrm{~S}$ & $0.25 \mathrm{~S}$ & $64 \mathrm{R}$ \\
\hline L77 & $0.125 \mathrm{~S}$ & $19 \mathrm{~S}$ & $>32 \mathrm{R}$ & $2 \mathrm{~S}$ & $4 S$ & $0.5 \mathrm{~S}$ & $8 \mathrm{R}$ & $2 \mathrm{I}$ & $8 \mathrm{~S}$ \\
\hline L314 & $0.25 \mathrm{~S}$ & $19 \mathrm{~S}$ & $>32 \mathrm{R}$ & $4 \mathrm{~S}$ & $32 \mathrm{R}$ & $0.5 \mathrm{~S}$ & $>32 \mathrm{R}$ & $0.25 \mathrm{~S}$ & $16 \mathrm{I}$ \\
\hline
\end{tabular}

Key: $\mathrm{S}=$ Sensitive; $\mathrm{I}=$ Intermediate; $\mathrm{R}=$ Resistant.

\section{Discussion}

Actinomycetes are opportunistic microorganisms causing infections in immunocompromised patients particularly, human immunodeficiency virus (HIV)infected individuals. Pulmonary infections caused by these organisms display symptoms that mimic tuberculosis hence can easily be mistaken for Mycobacteria tuberculosis. Identification of Actinomycetes is based on a variety of phenotypic, chromatographic, and genotypic characteristics. Increased awareness of Actinomycetes can greatly improve chances for rapid and correct diagnosis. Basic and clinical analysis is necessary for appropriate treatment.

Three hundred and eighty five samples were collected from patients of different age groups. Out of 385 samples collected, 52 (14\%) of them had Actinomycetes. The youngest positive case was 17 years and the oldest being 80 years old. Male were the most affected gender with $33 / 52$ (63\%) and female were 19/52 (37\%). Thirty nine (75\%) of the cases had a history of TB treatment (either on treatment, finished treatment, retreatment) while 13 (25\%) had no history of TB treatment. 
Direct smears of all the samples were stained using gram stain. Out of these, 88 showed microscopic characteristics of Actinomycetes, i.e, gram-positive with filamentous branching structures which fragment into bacillary or coccoid forms [2].

These 88 suspects were further investigated by culture and biochemical tests and 52 were confirmed as Actinomycetes. All 52 grew well in aerobic conditions at $35^{\circ} \mathrm{C}$ in SDA and a non-selective medium, $\mathrm{MH}$ agar. The colonies exhibited a typical hard to pick from the culture medium with few mucoid. Some exhibited white wrinkled colonies, or greyish whitish chalky colonies typical of Actinomycetes [7] [8] [9].

Actinomycetes have the ability to produce a variety of extracellular hydrolytic enzymes [10], hence, biochemical tests help in the identification of different Actinomycetes. Catalase test, citrate utilization, urease test and casein hydrolysis were the biochemical test done in this study. All the 52 isolates were catalase positive and were able to utilize citrate as the sole carbon source. Most of them were able to produce urease enzyme while only a few of them were able to hydrolyze casein. These characteristics agree with some of the characteristics described by some studies in literature [8].

Molecular analysis of Actinomycetes is very important as it helps to confirm their identification and to further their investigation. This analysis was done by extracting DNA from the isolates that had morphological and biochemical characteristics of Actinomycetes. The extracted DNA was then Amplified using specific primers for $16 \mathrm{~S}$ rRNA. Out of the 52 isolates that had characteristics of Actinomycetes, only $32(61.5 \%)$ isolates were able to be amplified by the pair of primers used yielding a band size of about 1300 base pairs.

Antimicrobial susceptibility testing of aerobic Actinomycetes isolated from clinical specimens is very important as it can help in guiding the therapy for infections. Actinomycetes are slow growing and most of them clumps and aggregates hence causing difficulty in carrying out the antimicrobial susceptibility testing [11] [12]. Broth microdilution method was used to perform the AST which is the approved standard method by CLSI for antimicrobial susceptibility testing of Actinomycetes [6]. Interpretation of the MICs was done according to CLSI guidelines.

This study determined the antimicrobial susceptibility patterns of 52 clinical isolates of aerobic Actinomycetes which were identified by phenotypic features.

Most of the isolates were susceptible to most antibiotics. Gentamycin showed the highest susceptibility (100\%) followed by Ciprofloxacin (98\%), Co-trimoxazole (Trimethoprim-Sulphamethoxazole) (94\%) and Amikacin (90\%). These findings are almost similar to those observed by Hashemi-Shahraki [13] on a study done on Nocardia species. A study done by Hamid [14] on Streptomyces species also showed over $90 \%$ susceptibility to Gentamycin. Another study by Silva [15] on Rhodococcus species also showed $100 \%$ susceptibility to Gentamycin.

Trimethoprim-sulphamethoxazole is the commonly used antibiotic for aero- 
bic Actinomycetes [14] [16] [17] [18]. Our study showed that most of the isolates (94\%) were susceptible to Trimethoprim-sulphamethoxazole which is in agreement with several other studies done on aerobic Actinomycetes [12] [19] [20]. However, resistance to Trimethoprim-sulphamethoxazole has been observed in different studies [11] [14] [15] [17] [18] [21] among others. This is on the contrary to the current study. The resistance could be as a result of overuse of this antibiotic.

On the other hand, most of the isolates were less susceptible to Doxycycline, Linezolid, Amoxicillin-clavulanate, Clarithromycin and Ceftriaxone. A study by Hashemi-Shahraki [13] on Nocardia species also showed less susceptibility to Ceftriaxone, which is consistent with the results of our study. However, a study by Hashemi-Shahraki et al. [13] showed high resistance to Amoxicillin-clavulanate and Ciprofloxacin which is on the contrary to our study. Another study done on Gordonia by Moser et al., [21] showed susceptibility to Ceftriaxone, Clarithromycin, Linezolid, Amikacin, Amoxicillin-Clavulanate and Ciprofloxacin. Resistance to Ceftriaxone was observed on a study done on Streptomyces [22] which is on the contrary to the current study.

Resistance to three or more antibiotics was considered multidrug-resistant [11]. Therefore, 4 (7.6\%) isolates showed multidrug resistance pattern, being resistance to more than 3 antibiotics; Amoxicillin-Clavulanate, Ceftriaxone, and Linezolid. Ceftriaxone and Clarithromycin had the highest resistance of $11.5 \%$ and $26.9 \%$ respectively.

All the antimicrobial agents studied in this study were effective in inhibiting the growth of most Actinomycetes tested. The antimicrobial activity of all the antibiotics tested against the isolates was statistically significant with $\mathrm{P}$ value less than $0.001(\mathrm{P}<0.001)$.

\section{Conclusion}

The findings of this study show that there is a significant Actinomycotic infection in TB smear-negative and retreatment cases. This could be the reasons for persistent symptoms despite treatment. In most TB screening facilities, diagnosis of Actinomycetes is not done due to the lack of technical capability for diagnosis. Misdiagnosis and wrong treatment could be a significant factor in the high morbidity and mortality associated with TB management. Therefore, investigating all suspected pulmonary pathologies for potential Actinomycetes and other infection is recommended. Though most antibiotics tested in this study were susceptible, resistance to a few antibiotics was observed; hence, proper screening and antimicrobial susceptibility testing of Actinomycetes is very important for guiding therapeutic decisions.

\section{Limitations of the Study}

Due to financial constraints, full genome sequencing of the isolated Actinomycetes could not be done. This would have provided more information especially 
on determining the specific species hence better understanding of the species diversity of Actinomycetes in TB-smear negative and retreatment cases.

\section{Acknowledgements}

We would like to thank the Kenya Medical Research Institute's Mycology lab for allowing us to do the work there. The first author would also want to thank the lab staff for their assistance and her colleagues for offering a helping hand when she needed it.

\section{Conflicts of Interest}

The authors do not have any conflict of interest.

\section{References}

[1] Aghamirian, M.R. and Ghiasian, S.A. (2009) Isolation and Characterization of Medically Important Aerobic Actinomycetes in Soil of Iran (2006-2007). The Open Microbiology, 13, 53-57. https://doi.org/10.2174/1874285800903010053

[2] Sullivan, D.C. and Chapman, S.W. (2010) Bacteria that Masquerade as Fungi: Actinomycosis/Nocardia. Proceedings of the American Thoracic Society, 7, 216-221. https://doi.org/10.1513/pats.200907-077AL

[3] Rao, K.V., Rao, D.B. and Rao, T.R. (2012) Isolation and Characterization of Antagonistic Actinobacteria from Mangrove Soil. Journal of Biochemical Technology, 3.

[4] Kumar, V., Bharti, A., Gusain, O. and Bisht, G.S. (2010) An Improved Method for Isolation of Genomic DNA from Filamentous Actinomycetes. Journal of Engineering and Technology Management, 2, 10-13.

[5] Monciardini, P., Sosio, M., Cavaletti, L., Chiocchini, C. and Donadio, S. (2002) New PCR Primers for the Selective Amplification of $16 \mathrm{~S}$ rDNA from Different Groups of Actinomycetes. FEMS Microbiology Ecology, 42, 419-429.

[6] NCCLS (2003) Susceptibility Testing of Mycobacteria, Nocardiae and Other Aerobic Actinomycetes, Approved Standard. NCCLS Document M-24A. NCCLS, Wayne, PA.

[7] Rana, S. and Salam, M.D. (2014) Antimicrobial Potential of Actinomycetes Isolated from Soil Samples of Punjab, India. Journal of Microbiology \& Experimentation, 1, 63-68. https://doi.org/10.15406/jmen.2014.01.00010

[8] Sharma, M., Dangi, P. and Choudhary, M. (2014) Actinomycetes: Source, Identification, and Their Applications. International Journal of Current Microbiology and Applied Sciences, 3, 801-832. https://doi.org/10.20546/ijcmas.2017.602.089

[9] Opande, G., Were, O. and Arama, P. (2013) Use of Soil Streptomycetes from Maseno (Kenya) to Inhibit Growth of Pyricularia Grisea invitro Cultures. Journal of Agriculture and Veterinary Science, 6, 1-6. https://doi.org/10.9790/2380-0610106

[10] Saadoun, I., Rawashdeh, R., Dayeh, T., Ababneh, Q. and Mahasneh, A. (2007) Isolation, Characterization and Screening for Fiber Hydrolytic Enzymes-Producing Streptomycetes of Jordanian Forest Soils. Biotechnology, 6, 120-128. https://doi.org/10.3923/biotech.2007.120.128

[11] Condas, L.A.Z., Ribeiro, M.G., Muro, M.D., Vargas, A.P.C.D., Matsuzawa, T., Yazawa, K., Ferreira, K.S., et al. (2015) Molecular Identification and Antimicrobial Resistance Pattern of Seven Clinical Isolates of Nocardia Spp. in Brazil. Revista do Instituto de Medicina Tropical de São Paulo, 57, 251-256. 
https://doi.org/10.1590/S0036-46652015000300012

[12] Glupczynski, Y., Berhin, C., Janssens, M. and Wauters, G. (2006) Determination of Antimicrobial Susceptibility Patterns of Nocardia Spp. from Clinical Specimens by Etest. Clinical Microbiology and Infection, 12, 905-912. https://doi.org/10.1111/j.1469-0691.2006.01460.x

[13] Hashemi-Shahraki, A., Heidarieh, P., Bostanabad, S.Z., Hashemzadeh, M., Feizabadi, M.M., Schraufnagel, D. and Mirsaeidi, M. (2015) Genetic Diversity and Antimicrobial Susceptibility of Nocardia Species among Patients with Nocardiosis. Scientific Reports, 5, Article No. 17862. https://doi.org/10.1038/srep17862

[14] Hamid, M.E. (2011) Variable Antibiotic Susceptibility Patterns among Streptomyces Species Causing Actinomycetoma in Man and Animals. Annals of Clinical Microbiology and Antimicrobials, 10, Article No. 24. https://doi.org/10.1186/1476-0711-10-24

[15] Silva, P.D., Miyata, M., Sato, D.N., Santos, A.C.B., Mendes, N.H. and Leite, C.Q.F. (2010) Rhodococcus equi Isolation from Sputum of Patients with Suspected Tuberculosis. Memórias do Instituto Oswaldo Cruz, 105, 199-202. https://doi.org/10.1590/S0074-02762010000200015

[16] Van de Sande, W.W., Fahal, A.H., Goodfellow, M., Welsh, O. and Zijlstra, E.E. (2014) Merits and Pitfalls of Currently Used Diagnostic Tools in Mycetoma. PLoS Neglected Tropical Diseases, 8, e2918. https://doi.org/10.1371/journal.pntd.0002918

[17] Uhde, K.B., Pathak, S., McCullum Jr., I., Jannat-Khah, D.P., Shadomy, S.V., Dykewicz, C.A., Brown, J.M., et al. (2010) Antimicrobial-Resistant Nocardia Isolates, United States, 1995-2004. Clinical Infectious Diseases, 51, 1445-1448.

https://doi.org/10.1086/657399

[18] Zampella, J.G., Kwatra, S.G., Kazi, N. and Aguh, C. (2017) Madura Foot Caused by Gordonia terrae Misdiagnosed as Nocardia. Australasian Journal of Dermatology, 58, e129-e131. https://doi.org/10.1111/ajd.12516

[19] McTaggart, L.R., Doucet, J., Witkowska, M. and Richardson, S.E. (2015) Antimicrobial Susceptibility among Clinical Nocardia Species Identified by Multilocus Sequence Analysis. Antimicrobial Agents and Chemotherapy, 59, 269-275. https://doi.org/10.1128/AAC.02770-14

[20] Lowman, W. and Aithma, N. (2010) Antimicrobial Susceptibility Testing and Profiling of Nocardia Species and Other Aerobic Actinomycetes from South Africa: Comparative Evaluation of Broth Microdilution versus the Etest. Journal of Clinical Microbiology, 48, 4534-4540. https://doi.org/10.1128/JCM.01073-10

[21] Moser, B.D., Pellegrini, G.J., Lasker, B.A. and Brown, J.M. (2012) Pattern of Antimicrobial Susceptibility Obtained from Blood Isolates of a Rare but Emerging $\mathrm{Hu}$ man Pathogen, Gordonia Polyisoprenivorans. Antimicrobial Agents and Chemotherapy, 56, 4991-4993. https://doi.org/10.1128/AAC.01251-12

[22] Pellegrini, G.J., Graziano, J.C., Ragunathan, L., Bhat, M.A., Hemashettar, B.M. and Brown, J.M. (2012) Scalp Abscess Due to Streptomyces cacaoi Subsp. cacaoi, First Report in a Human Infection. Journal of Clinical Microbiology, 50, 1484-1486. https://doi.org/10.1128/JCM.06372-11 